\title{
Article
}

\section{The Effect of a Mixed Circuit of Aerobic and Resistance Training on Body Composition in Older Adults-Retrospective Study}

\author{
Anna Pieczyńska ${ }^{1}$ D , Ewa Zasadzka ${ }^{1, *(D)}$, Tomasz Trzmiel ${ }^{1}\left(\mathbb{D}\right.$, Małgorzata Pyda $^{2}$ and Mariola Pawlaczyk $^{3}$ \\ 1 Department of Occupational Therapy, Poznan University of Medical Sciences, 60-781 Poznań, Poland; \\ apieczynska@ump.edu.pl (A.P.); ttrzmiel@ump.edu.pl (T.T.) \\ 2 First Department of Cardiology, Poznan University of Medical Sciences, 61-848 Poznań, Poland; \\ malgorzatapyda@ump.edu.pl \\ 3 Department and Division of Practical Cosmetology and Skin Diseases Prophylaxis, \\ Poznan University of Medical Sciences, 60-623 Poznań, Poland; mariolapawlaczyk@ump.edu.pl \\ * Correspondence: ezasad@ump.edu.pl; Tel.: +61-854-65-73
}

Citation: Pieczyńska, A.; Zasadzka, E.; Trzmiel, T.; Pyda, M.; Pawlaczyk, M. The Effect of a Mixed Circuit of Aerobic and Resistance Training on Body Composition in Older

Adults-Retrospective Study. Int. J. Environ. Res. Public Health 2021, 18, 5608. https://doi.org/10.3390/ ijerph18115608

Academic Editors: Elisabetta Marini, Luis Alberto Gobbo and Paul B. Tchounwou

Received: 14 April 2021

Accepted: 23 May 2021

Published: 24 May 2021

Publisher's Note: MDPI stays neutral with regard to jurisdictional claims in published maps and institutional affiliations.

Copyright: (c) 2021 by the authors. Licensee MDPI, Basel, Switzerland. This article is an open access article distributed under the terms and conditions of the Creative Commons Attribution (CC BY) license (https:/ / creativecommons.org/licenses/by/ $4.0 /)$.
Abstract: Ageing is inevitably associated with body composition changes, such as loss of muscle mass, increase in the total fat mass, and unfavorable reduction of subcutaneous fat. Physical activity exerts significant effects on the body composition. The aim of the study was to investigate the effects of two different weekly doses of resistance-aerobic training on the body composition in older people. The study consisted in a retrospective data analysis of fitness club members aged $\geq 60$. The trainees participated in resistance-aerobic training sessions two or three times/week for a minimum of two months. A body composition analysis was performed before and after the training sessions. Group 1 (36 subjects) and Group 2 (28 subjects) had two and three training sessions/week, respectively. A higher skeletal muscle mass was found in Group 1 and lower waist-hip-ratio indices were observed in Group 2. No statistically significant differences were found in the body mass, skeletal muscle mass, fat mass, total body water, lean mass, body mass index, visceral fat area between both groups. The number of training session/week proved to be statistically insignificant for all investigated variables. Resistance-aerobic training with two sessions/week may be as effective in maintaining proper body composition in older people as the same training at the dose of three sessions/week.

Keywords: body composition; exercise training; older adults; physical activity

\section{Introduction}

Ageing is inevitably associated with unfavorable changes in body composition, such as loss of muscle mass, increase in the total fat mass, and reduction of subcutaneous fat. Accumulation of visceral fat, liver fat, and muscle fat infiltration also accompany the process of ageing [1]. Body composition has been demonstrated to affect numerous health aspects in older subjects, e.g., higher muscle mass lowers the risk of motor handicap [2]. Muscle fat infiltration has been linked to higher mortality [3], while excessive waist circumference may lead to frailty [4]. Ageing-related changes in body composition (muscle mass loss and accumulation of fat mass) may result in sarcopenic obesity, which is an increasingly common occurrence in ageing populations [5].

Thus, maintenance of proper body composition seems to be a particularly important aspect of healthy ageing. According to a systematic review and a meta-analysis of the available literature conducted by Liberman et al. [6], physical activity exerts a significant effect on body composition among older populations. In addition, these authors emphasize the need for further analysis of various methods of training.

Advanced age is associated with a higher risk for coronary heart diseases and the related mortality. Older people are more likely to experience complications after a cardiac 
incident or major surgery due to low fitness and activity [7]. Physical activity, whose beneficial effects on health in that age group have been demonstrated by numerous studies, may result in improved indices of cardiovascular health [8,9], but it is vital to select a suitable type of physical activity.

Resistance training is among the most widely recommended forms of physical activity for older populations. It slows down the loss of muscle mass [10-12], and favorably affects functional independence [13], cognitive abilities [14] and self-esteem [15]. Resistance training may prevent the onset of type-2 diabetes or play a role in its treatment, lower blood pressure, regulate lipid balance, and increase bone tissue density [16]. The literature offers reports that resistance training may also alleviate ageing-related limitations in functional mobility, improve static and dynamic balance, as well as lower the risk of falling [10].

Aerobic (cardio) training, which increases aerobic capacity, lowers blood pressure $[17,18]$ and serum lipid levels [19] — resulting in higher cardiovascular capacity [20]—is another important form of physical activity. In addition, it increases the insulin sensitivity by reducing the fat mass [21]. Combined training has also a beneficial effect on cardiometabolic risk factors, hemodynamics, and physical performance in the elderly group [22]. Both, endurance and resistance training display beneficial effects on arterial size, function, and wall thickness [23]. Therefore, it seems advisable to combine these types of training in older subjects [24]. Exercise lowers the risk of death due to cardiovascular causes by exerting a beneficial effect on the vascular system, such as a better endothelial function and a better compliance of the vessel (reduced stiffness) [25]. Regular physical exercise decreases the resting heart rate, blood pressure, atherogenic markers, and increases the physiological cardiac hypertrophy [26]. Several recent studies demonstrated that physical activity is associated with lowered markers of inflammation, improved metabolic health, less risk for cardiac failure, and higher chances of survival [27-29]. In addition, physical activity has a positive effect on the pulmonary function and cardiorespiratory fitness, both of which may decrease with age [30,31].

The best health effects are achieved if both, type and dose of physical activity are taken into consideration. According to the World Health Organization (WHO) [32], people aged $\geq 65$ years should undertake at least $75 \mathrm{~min} /$ week of high-intensity aerobic exercise or $150 \mathrm{~min} /$ week of moderate-intensity aerobic exercise, or the equivalent of a combination of both. The WHO also recommends varied multicomponent physical activity that emphasizes functional balance and strength training at moderate or greater intensity, on three or more days a week, to enhance functional capacity and to prevent falls [32]. Regular, moderate physical activity of older people improves their physical performance and helps prevent the frailty syndrome [33]. An example of mixed training is our mixed circuit, which consists of eight strength exercises to strengthen the main muscle groups and two aerobic exercises (cross walker and ergometer). There are several reasons why it is prudent to attempt and define the optimal dose of training for older trainees, chief among them the fact that excessive training will seem as an unattainable goal, and as such will be discouraging, whereas an insufficient amount of training will not bring the desired health effects. Guidelines regarding the number of training sessions might encourage older people to undertake regular exercise, resulting in optimal health effects.

The aim of the study was to analyze the effect of two different regimens of strengthendurance training (two or three sessions per week) and its relationship with the following body mass parameters: skeletal muscle mass, fat mass, total body water, lean body mass, percent body fat, waist-hip ratio, and visceral fat area in the age group of $\geq 60$ years.

\section{Materials and Methods}

\subsection{Data Eligibility}

The study was retrospective in nature. We analyzed data from one of the fitness clubs in the city of Poznan (Poland, Wielkopolskie Region) about their trainees between 2017-2020. The study included city-dwellers (population: $>500,000$ ), with high social and economic status, secondary or higher education, no contraindications for strengthendurance training. Data collection and analysis for the purpose of the study was con- 
ducted in February 2020. The data had been collected by one trainer and anonymized before submission. Inclusion criteria: age $\geq 60$ years, no health contraindications for training, ability to exercise properly and independently. Exclusion criteria: training lasting less than two months, lack of regularity in exercise, participation in additional sports activities, lack of body weight analysis before or after training, undertaking other structured exercises within 6 months before our study. The chart of data inclusion is presented in Figure 1.

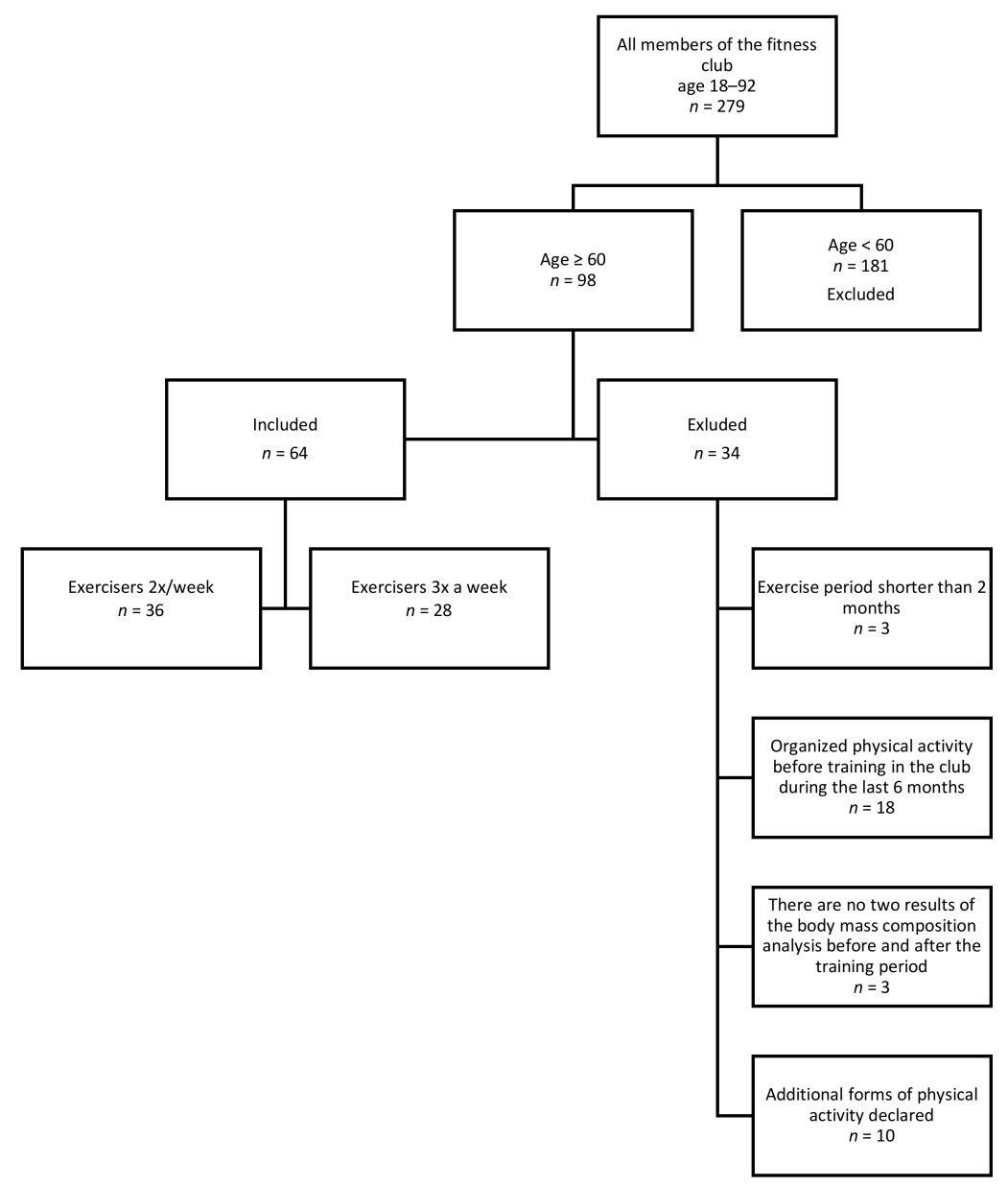

Figure 1. Criteria for including data for further analysis.

\subsection{Description of the Resistance-Aerobic Training}

One (circuit) training session lasted exactly 36 min for each study participant and included eight workout stations ( 2 for aerobic and 6 for resistance). The following workout stations were used:

- $\quad$ 1. Knee extensor muscles;

- $\quad$ 2. Chest muscle training;

- 3. Upper back muscle training;

- $\quad$ 4. Stationary bike;

- $\quad$ 5. Knee flexor muscles;

- 6. Abdominal muscle training;

- 7. Erector spinae training;

- 8. Elliptical trainer.

Resistance-aerobic exercises lasted 1 and $4 \mathrm{~min}$, respectively, with a 30-s interval between the workout stations. Two circuits, with a recommended break of $1 \mathrm{~min}$, were performed during a training session. The training group included a maximum of 8 participants at a given time. 
The resistance exercise load was delivered by the machine during the concentric and eccentric muscle contraction. The tempo was set by coordinating the movements of the trainee with the graphic representation on the machine screen to ensure that each trainee performed 15 repetitions of a given exercise in the course of $1 \mathrm{~min}$. The training plan is presented in Figure 2.

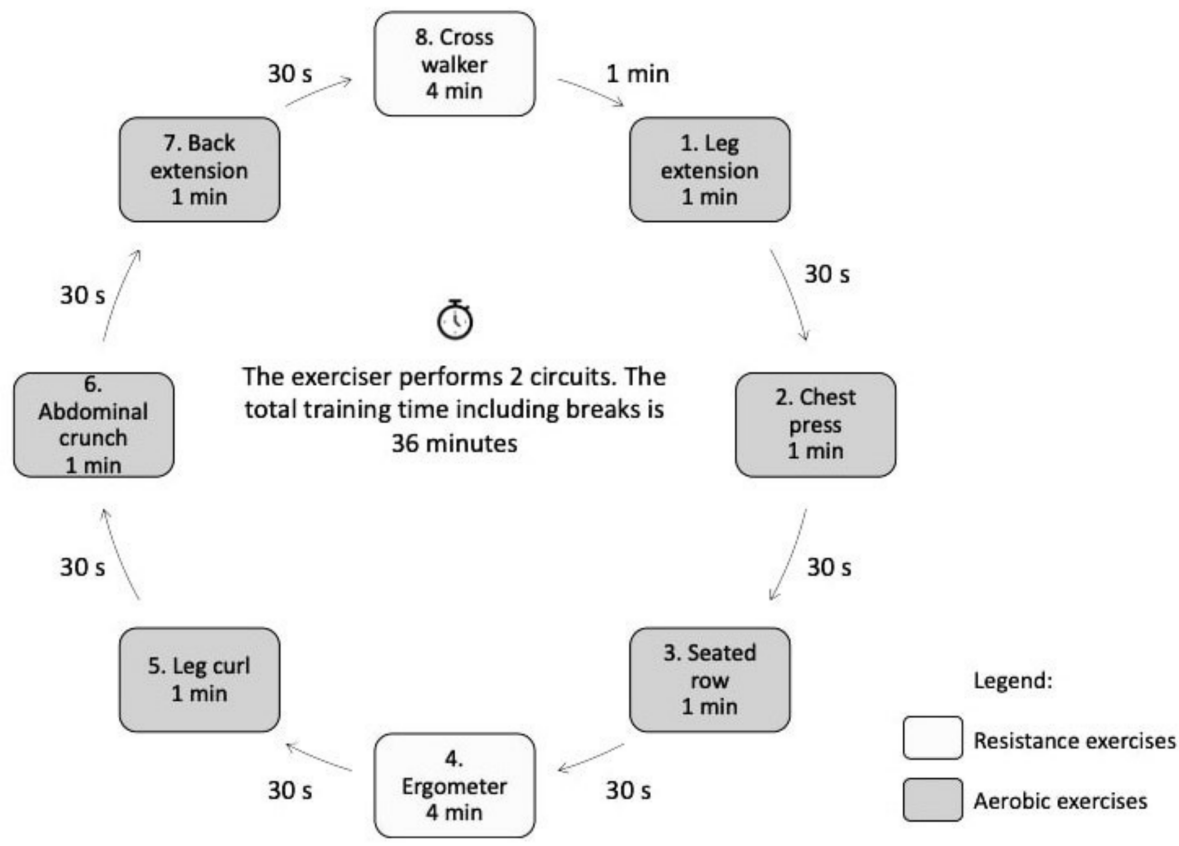

Figure 2. Training scheme.

The initial load value was individually adjusted during the first training session by measuring the maximal strength (it was possible due to electric engines which replaced standard weights) and was $40 \%$ of the mean maximum value. Each trainee started his or her training session with a higher eccentric contraction load, which was $130 \%$ of the concentric contraction value. As for aerobic training, the load was calibrated using a pulsometer for the exercises to be performed within the range of $60-70 \%$ of the maximum heart rate (HR max). The HR max was calculated using the following formula: HR max $=210-(0.5 \times$ age $)-(0.022 \times$ weight in $\mathrm{kg})$ for women and HR max $=210-$ $(0.5 \times$ age $)-(0.022 \times$ weight in $\mathrm{kg})+4$ for men [34]. A certified physiotherapist-trainer supervised each training to monitor performance and load. Every two weeks, the load on the resistance machines was increased by $1 \mathrm{~kg}$, if the condition of the trainee allowed it.

\subsection{Analysis of Body Composition}

The body composition was evaluated with the bioelectric impedance analysis using the eight-point tactile electrode system InBody 170 . The parameters directly measured by InBody are: impedance $(Z)$, reactance $\left(X_{c}\right)$, and phase angle. $Z$ is the impedance, or resistance in the human body, $X_{c}$ is the reactance which is the resistance in the condenser. The condenser in the human body is the cell membrane. Impedance is the sum of the vector of reactance $\left(X_{c}\right)$ and resistance $(R)$ and, when this sum is expressed in degrees, it is called a phase angle. The analyzer evaluates lean body mass and the percentage of fat mass on the basis of segmental multi-frequency analysis, separately for the torso and each limb. This equipment was used by other authors as well to determine the body composition of older subjects $[35,36]$. 
Description of the InBody machine and measurement performed:

- Direct segmental measurement of body mass composition;

- 8-point tetra-polar tactile electrode system (2 electrodes of the left foot, 2 electrodes of the right foot, 2 electrodes of the left hand, 2 electrodes of the right hand);

- Frequency-20,100 kHz;

- Volume-200 uA;

- Measurement duration-30 s;

- Body mass limit-5-250 kg;

- Age limit-1-99;

- Height limit-50-250 cm.

The identification number, age, sex and height of the participants were entered into the analyzer. After all metal accessories and heavy clothing have been removed, the participants mounted the platform and positioned their feet on the designated spots with four electrodes, and griped the two handles (two electrodes in each handle, one for the thumb and one for the rest of the hand). The upper limbs were straight, abducted by 30-45 degrees from the torso. The machine provides information on the Body Mass Index (BMI), calculated as body weight quotient (in $\mathrm{kg}$ ) to squared body height (in $\mathrm{m} 2$ ), skeletal muscle mass (SMM), fat mass (FAT), total body water (TBW), lean body mass (LBM), waist-hip ratio (WHR) and visceral fat area (VFA). The height (barefoot) and body weight (in light clothing) were measured with the accuracy of $0.1 \mathrm{~cm}$ and $0.1 \mathrm{~kg}$, respectively. The measurements were taken by a certified dietitian. The subjects refrained from eating and drinking for a minimum of $8 \mathrm{~h}$ prior to the measurement. The analysis was always conducted in the morning. The participants were required to abstain from physical activity (no training sessions) one day before the measurements were taken.

\subsection{Ethical Issues}

Study approval and confirmation of its non-experimental nature were obtained from the Local Ethics Committee. The Declaration of Helsinki was followed. Written informed consent to use anonymized data of club members, who earlier consented to data collection by the club, was obtained from the club owner.

\subsection{Statistical Analysis}

Statistical analysis was conducted using the Jamovi software (v.0.8.1.5), (Jamovi project, Sydney, NSW, Australia). In the absence of normal distribution of the investigated variables, the Mann-Whitney test was used to compare the groups before training. The General Linear Model was used to control for the following variables: sex, age and number of months in training. The analysis was conducted to assess the effect of the number of training sessions per week on the body mass composition for each variable. The $p$-value of $<0.05$ was considered as statistically significant. A design with group sample sizes of 30 and 19, respectively, can detect effect sizes of $\delta \geq 0.99$ with a probability of at least 0.911 , assuming a two-sided criterion for detection that allows for a maximum type I error rate of $\alpha=0.05$.

\section{Results}

A total of 64 subjects (36-Group 1 and 28-Group 2) were included in the study. Groups 1 and 2 had two and three training sessions/week, respectively. The majority of the participants were female (64\% and $57 \%$ in groups 1 and 2, respectively). The time of participation in the training is presented in Table 1 . This variable was controlled when testing the effect of the training frequency. The study population characteristics at baseline are presented in Table 2. No significant differences in age and body composition were found between both groups at baseline. The results at baseline and after the last training were compared between both groups (Table 3). The mean body weight, tissue mass and BMI were lower in all subjects. A reduced area of visceral fat and percentage of fat mass were observed. The mean water weight and lean body mass were slightly lower. A higher 
skeletal muscle mass was found in Group 1 ( 2 training sessions/week) and lower WHR indices were observed in Group 2 ( 3 training sessions/week). No statistically significant differences were found in the body mass, SMM, FAT, TBW, LBM, BMI, VFA (at baseline and after the last training) between both groups (Table 3). A statistically significant reduction in the percentage of body fat and WHR was observed in Group 2.

Table 1. Time of participation in training in months.

\begin{tabular}{cccc}
\hline Group & Mean & SD & Median \\
\hline$<6$ months & 2.15 & 2.02 & 2 \\
\hline $6-12$ months & 9.51 & 1.71 & 10 \\
\hline$>12$ months & 20.58 & 7.40 & 18 \\
\hline Abbreviations: SD-standard deviation &
\end{tabular}

Abbreviations: SD—standard deviation.

Table 2. Participant characteristics at baseline.

\begin{tabular}{|c|c|c|c|c|c|c|c|}
\hline \multirow[b]{2}{*}{$\begin{array}{l}\text { Parameters } \\
(\mathrm{m} \pm \mathrm{SD})\end{array}$} & \multicolumn{3}{|c|}{ Training 2x/week } & \multicolumn{3}{|c|}{ Training $3 x /$ week } & \multirow[b]{2}{*}{$p^{a}$} \\
\hline & $\begin{array}{c}\text { Total } \\
n=36\end{array}$ & $\begin{array}{c}\text { Women } \\
n=23\end{array}$ & $\begin{array}{c}\text { Men } \\
n=13\end{array}$ & $\begin{array}{c}\text { Total } \\
n=28\end{array}$ & $\begin{array}{c}\text { Women } \\
n=16\end{array}$ & $\begin{array}{c}\text { Men } \\
n=12\end{array}$ & \\
\hline Age years & $69 \pm 6$ & $68 \pm 5$ & $71 \pm 8$ & $71 \pm 7$ & $72 \pm 8$ & $70 \pm 5$ & 0.255 \\
\hline Body mass kg & $81.0 \pm 16.6$ & $76.8 \pm 14.5$ & $88.6 \pm 18.1$ & $81.2 \pm 12.3$ & $77.6 \pm 10.5$ & $86.0 \pm 13.4$ & 0.611 \\
\hline $\mathrm{BMI} \mathrm{kg} / \mathrm{m}^{2}$ & $28.7 \pm 4.5$ & $29.0 \pm 5.0$ & $28.1 \pm 3.5$ & $28.9 \pm 3.9$ & $29.9 \pm 4.5$ & $27.6 \pm 2.8$ & 0.670 \\
\hline SMM kg & $29.0 \pm 7.1$ & $25.2 \pm 3.2$ & $35.7 \pm 7.3$ & $28.9 \pm 6.2$ & $24.4 \pm 1.0$ & $34.8 \pm 5.2$ & 0.802 \\
\hline FAT kg & $28.4 \pm 9.7$ & $30.5 \pm 10.1$ & $24.6 \pm 8.1$ & $28.8 \pm 9.4$ & $32.5 \pm 10.1$ & $23.7 \pm 5.5$ & 0.887 \\
\hline TBW 1 & $38.6 \pm 8.9$ & $34.0 \pm 4.0$ & $47.0 \pm 9.1$ & $38.5 \pm 7.8$ & $33.0 \pm 1.3$ & $45.8 \pm 6.7$ & 0.929 \\
\hline LBM kg & $52.6 \pm 12.1$ & $46.2 \pm 5.5$ & $63.9 \pm 12.4$ & $52.4 \pm 10.4$ & $45.1 \pm 1.7$ & $62.3 \pm 8.9$ & 0.941 \\
\hline $\mathrm{PBF} \%$ & $34.8 \pm 8.1$ & $38.9 \pm 6.2$ & $27.5 \pm 5.5$ & $35.2 \pm 9.2$ & $41.0 \pm 7.8$ & $27.5 \pm 3.2$ & 0.920 \\
\hline WHR & $0.9 \pm 0.05$ & $0.9 \pm 0.05$ & $0.9 \pm 0.05$ & $1.0 \pm 0.05$ & $0.9 \pm 0.06$ & $1.0 \pm 0.03$ & 0.178 \\
\hline VFA $\mathrm{cm}^{2}$ & $13.3 \pm 4.7$ & $14.5 \pm 4.6$ & $11.2 \pm 4.1$ & $13.7 \pm 5.3$ & $15.8 \pm 5.5$ & $11.0 \pm 3.5$ & 0.771 \\
\hline
\end{tabular}

Notes: ${ }^{\text {a }}$ Statistically significant differences in mean values of the investigated parameters between both groups, not controlled for age. Abbreviations: $\mathrm{m}$-mean, SD—standard deviation, BMI—Body Mass Index, SMM—skeletal muscle mass, FAT—fat mass, TBW—-total body water, LBM—lean body mass, PBF—-percent body fat, WHR—waist-hip ratio, VFA—visceral fat area.

Table 3. Mean differences in body composition between Groups 1 and 2.

\begin{tabular}{|c|c|c|c|c|c|}
\hline \multirow{2}{*}{ Parameters } & \multicolumn{4}{|c|}{ Mean Differences between Baseline and Last Training Results ( \pm SD) } & \multirow{2}{*}{$p^{\mathrm{a}}$} \\
\hline & \multicolumn{2}{|c|}{ 2x/week } & \multicolumn{2}{|c|}{$3 x /$ week } & \\
\hline Body mass kg & $-1.21 \pm 2.76$ & $-1.3 \%$ & $-1.95 \pm 3.15$ & $-2.6 \%$ & 0.258 \\
\hline SMM kg & $1.49 \pm 8.55$ & $+5.9 \%$ & $-0.07 \pm 1.19$ & $0.0 \%$ & 0.720 \\
\hline FAT kg & $-1.36 \pm 3.37$ & $-3.7 \%$ & $-1.90 \pm 2.98$ & $-8.3 \%$ & 0.368 \\
\hline TBW 1 & $-0.23 \pm 2.09$ & $-0.7 \%$ & $-0.02 \pm 1.46$ & $-0.2 \%$ & 0.461 \\
\hline LBM kg & $-0.32 \pm 3.13$ & $-0.7 \%$ & $-0.05 \pm 1.98$ & $-0.2 \%$ & 0.650 \\
\hline $\mathrm{BMI} \mathrm{kg} / \mathrm{m}^{2}$ & $-0.22 \pm 1.07$ & $-0.6 \%$ & $-0.54 \pm 1.03$ & $-2.1 \%$ & 0.230 \\
\hline $\mathrm{PBF} \%$ & $-0.57 \pm 2.22$ & $-1.4 \%$ & $-1.97 \pm 2.89$ & $-6.2 \%$ & 0.05 \\
\hline WHR & $0.00 \pm 0.01$ & $0.0 \%$ & $-0.02 \pm 0.02$ & $-1.6 \%$ & 0.006 \\
\hline VFA $\mathrm{cm}^{2}$ & $-0.73 \pm 2.02$ & $-4.0 \%$ & $-1.14 \pm 1.76$ & $-10.0 \%$ & 0.371 \\
\hline
\end{tabular}

Notes: ${ }^{\text {a }}$ Statistical significance of mean differences in body composition at baseline and after the last training in Groups 1 and 2. Abbreviations: $\mathrm{m}$ —mean, SD—standard deviation, BMI—Body Mass Index, SMM—skeletal muscle mass, FAT—fat mass, TBW—-total body water, LBM—lean body mass, PBF—percent body fat, WHR — waist-hip ratio, VFA—visceral fat area.

In addition, the effects of training frequency on body composition (controlled for sex, age and the number of months in training) were analyzed. The number of trainings/week proved to be statistically insignificant for all investigated variables (Table 4). 
Table 4. Analysis of the impact of the weekly number of workouts on body mass composition.

\begin{tabular}{ccccc}
\hline Parameters & Estimate $^{\mathbf{a}}$ & SE & $\mathbf{t}$ & $p$ \\
\hline BMI kg/m ${ }^{2}$ & 0.28 & 0.54 & 0.52 & 0.605 \\
SMM kg & -0.63 & 0.57 & -1.10 & 0.273 \\
FAT kg & -0.60 & 1.18 & -0.51 & 0.610 \\
TBW l & -0.71 & 0.72 & -0.99 & 0.324 \\
LBM kg & -1.01 & 0.99 & -1.02 & 0.309 \\
PBF \% & -0.78 & 0.86 & -0.91 & 0.364 \\
WHR & 0.00 & 0.01 & 0.20 & 0.839 \\
VFA cm & -0.57 & 0.63 & 0.90 & 0.370 \\
\hline
\end{tabular}

Notes: ${ }^{a}$ Controlled for sex, age, and number of training weeks. Abbreviations: BMI—Body Mass Index, SMMskeletal muscle mass, FAT—fat mass, TBW—-total body water, LBM—lean body mass, PBF—percent body fat, WHR — waist-hip ratio, VFA—visceral fat area.

\section{Discussion}

The literature demonstrates a marked lack of consensus on the optimal frequency of trainings per week for older populations. In particular, the number of studies investigating the optimal dose of resistance-aerobic training, whose positive effects on health in older people have been reported by numerous authors, is limited. In our study, we confirmed the beneficial effects of resistance-aerobic training. We used the BIA method to analyze the body weight composition, which is a fast, safe and non-invasive method to obtain quantitative estimates of the body composition. A multifrequency BIA and, specifically, bioimpedance spectroscopy is preferred for fluid volume measurements, although for a general body composition assessment, the BIA at $50 \mathrm{kHz}$ is more widely used [37]. In Group 1 (two sessions/week), the muscle mass increased on average by $5.9 \%$ (whereas in Group 2 no increase was observed). The body fat was reduced by $3.7 \%$ and $8.3 \%$ in Groups 1 and 2, respectively. A lower body fat percentage and reduction of the visceral fat area were also observed in both groups. Those changes may prove to be highly beneficial for older people, whose body composition has a crucial effect on the cardiovascular risk factors [5], and may prevent sarcopenic obesity [5,38,39].

Combination (resistance-aerobic) training had a favorable outcome in the entire study population, which is consistent with the reports of Timmons et al. [40] who demonstrated that resistance-aerobic training more effectively reduced the fat mass in older subjects $(-2.6 \%)$ as compared to resistance training or aerobic training alone $(-0.4 \%$ and $-2.2 \%$, respectively). These authors also proved its usefulness in increasing the gait speed and lower limb strength as compared to the other two types of training. Their study participants trained for 12 weeks, 3 times/week, for a total of $72 \mathrm{~min}$. In the study by Lima et al. [41], who compared the impact of the resistance-aerobic training with only resistance or only aerobic training on body composition, the subjects also trained 3 times/week. A significantly reduced body mass, abdominal and waist circumference, and 24-h ambulatory monitored blood pressure were revealed in both, aerobic and resistance-aerobic training groups. However, the body fat was reduced only in the latter. Schroeder et al. [42] compared the effect of resistance, aerobic and combination training on the risk factors for cardiovascular diseases (CVD), including muscle strength and body composition in 69 adults (mean age: $58 \pm 7$ years) with elevated risk for CVD. Combination training ( 3 times/week for $60 \mathrm{~min}$ ) resulted in a higher strength and lean body mass. Their study suggests that combination training may be more valuable than resistance training or aerobic training alone because it seems to have the most beneficial effect on the risk factors for CVD. The resistance training itself, performed 3 times a week may also reduce the risk of CVD in elder women as shown by Dos Santos et al. [43]. In their study, the participants were divided in two groups with different repetition zones. The results obtained for both groups indicated a lesser risk of developing a CVD in comparison with the control group not undergoing any training.

To the best of our knowledge, our study has been the first to investigate two different frequencies of resistance-aerobic training on various body mass elements in a population of healthy older community-dwellers. No statistically significant changes in body composition 
as compared to the weekly number of training sessions ( 2 or 3 times / week) were found for any of the investigated variables, controlled for sex, age, and number of training weeks. Statistically significant changes between Groups 1 and 2 ( 2 and 3 sessions /week, respectively) were observed only for the waist-hip ratio/WHR $(p=0.006)$, which decreased only in Group 2 by $1.6 \%$. The following parameters decreased in both groups: body weight, fat mass, visceral fat, percentage of fat tissue and BMI. Changes in muscle mass at baseline and after the last training were not statistically significant in both groups, although a $5.9 \%$ increase was detected in Group 1.

Fisher et al. [44] investigated the frequency of resistance-aerobic training in older women in the following subgroups: 1 aerobic and 1 resistance training session/week (group 1), 2 aerobic and 2 resistance training sessions/week (group 2), and 3 aerobic and 3 resistance training sessions/week (group 3). Similar changes in the body mass composition (higher lean body mass and lower percentage of fat mass and BMI) were found in all three subgroups.

Most reports on the recommended training dose for older people concern resistance training. Nascimento et al. [45] investigated 45 women (age $\geq 60$ years) who participated in resistance training for 12 weeks (8 exercises, $10-15$ repetitions) and also found no differences between groups with 2 and 3 sessions/week. The muscle mass increase was comparable in both groups ( $+5.5 \%$ for 2 sessions/week and 5.8\% for 3 sessions/week), but, unlike in our study, the change was statistically significant $(p<0.001)$. Similar changes in the lean body mass were reported by Murlasits et al. [46] for groups with different training frequency. They investigated 29 people over the age of 60 years undergoing resistance training 2 or 3 times per week, for 8 weeks. Pina et. al. [47] also found no change in the lean body mass in groups training 2 or 3 times per week. Thalainen et al. [48] analyzed people aged 65-75 years who were assigned to groups training 1, 2 or 3 times/week and non-training controls, and found that a training frequency over 2 times/week may help maintain adequate fat mass levels. Turpela et al. [49] analyzed the effects of various frequencies of resistance training on body composition and functional capabilities in elderly subjects. A total of 106 people, aged 64-75 years, were randomly assigned to one of four groups (1, 2 or 3 times/week and non-training controls). All subjects from the three study groups participated in a full-body resistance training (2-5 series, 4-12 repetitions/exercise, 7-9 exercises/session) and no significant changes in the body composition were observed. These authors concluded that functional capabilities may be improved using the 2 sessions/week regime. The advantage of resistance training 3 times a week over training once a week in an obese female population was demonstrated by Toselli et al. [50]. The authors showed that, although body weight, waist circumference and body fat percentage decreased statistically significantly in both groups, only in the group training 3 times a week there was also an increase in muscle strength (measured with a hand dynamometer) and the phase angle. Huang et al. [51] demonstrated that medium-intensity aerobic training (66-73\% heart rate reserve, 40-50 min/session, 3-4 days/week) is an optimal and effective dose for maximal cardiorespiratory benefits in healthy sedentary older adults. In our study, no statistically significant changes in body composition between Groups 1 and 2 were observed, although higher muscle mass was detected only in Group 1, which may be indicative of an advantage of the 2 over 3 sessions/week training regime. As mentioned above, the literature lacks consensus on the optimal training dose and conflicting reports, recommending 2 as well as 3 sessions/week, may be found.

The search for the optimal training dose seems to be especially important as far as older populations are concerned. Time is one of the barriers to physical activity in that age group [52], so medium-frequency training, e.g., 2 sessions/week, might be an incentive for more older people to engage in physical activity, while still preserving all benefits of the regular training. Fisher et al. [53], in their review, recommend the minimal training dose (e.g., $\leq 60 \mathrm{~min}, 2$ times/week), which may later be adjusted, if necessary. These authors demonstrated that even simple resistance training at the dose of $<60 \mathrm{~min}, 2$ times / week, is sufficient to be beneficial for the health. They also emphasize the necessity of breaks 
and regeneration between the sessions, so as not to cause overtraining, which will not be the case if minimal training doses (2 times/week) are recommended. The findings of our present study indicate that similar recommendations may be beneficial also in case of resistance-aerobic training. The training, apart from the abovementioned health benefits, is also associated with another positive aspect: the exercises are performed in groups of 8 people, allowing older subjects, who often feel lonely, to acquire and foster new social contacts. Other authors point to physical activity as a factor which either protects against the development of depressive symptoms and fear, or lowers their intensity among other people, consequently improving their quality of life [54-56]. Kekäläinen et al. [57] claim that participation in resistance training sessions 2 times/week is the most beneficial for various aspects of psychical functioning of older populations.

Our study is not without limitations, chief among them is the lack of control over the dietary habits and daily physical activity, e.g., the number of steps/day of the study participants. Despite the fact that the subjects were instructed not to engage in additional exercises, their daily physical activity levels connected with normal everyday functioning, may have impacted the final results. In addition, most investigations which were used as a reference for our findings conducted body measurements with Dual-energy X-ray Absorptiometry (DXA), whereas our analysis was based on the bioelectric impedance method. The measurement tool used in our study calculates the bioimpedance. However, in recent years, the bioimpedance vector analysis (BIVA) has been increasingly used for the assessment of body composition. BIVA is considered to be free from errors associated with prediction equations as it interprets the raw bioimpedance value resistance $(R)$ and reactance $\left(X_{c}\right)[58]$.

\section{Conclusions}

This study demonstrated that resistance-aerobic training (2 sessions/week) may be as effective in maintaining proper body composition in older people as the same training at the dose of 3 sessions/week. It is a novel approach as other authors have focused on defining the optimal dose of resistance training alone. In addition, evidence that 2 rather than 3 trainings will suffice to bring about positive health changes may help and break the time-barrier argument and encourage more older subjects to undertake physical activities. Further large-sample studies to investigate the resistance-aerobic training, whose beneficial effects for the health of older populations were confirmed by numerous sources, are necessary.

Author Contributions: Conceptualization: A.P., T.T. and M.P. (Mariola Pawlaczyk); methodology: A.P. and E.Z.; formal analysis: A.P. and T.T.; investigation: A.P., T.T. and E.Z.; writing-original draft preparation: A.P., T.T., E.Z. and M.P. (Małgorzata Pyda); writing-review and editing: M.P. (Małgorzata Pyda) and M.P. (Mariola Pawlaczyk); supervision: M.P. (Mariola Pawlaczyk). All authors have read and agreed to the published version of the manuscript.

Funding: This research received no external funding.

Institutional Review Board Statement: Ethical review and approval were waived for this study, because it is not a medical experience (approved by Poznan University of Medical Science Bioethics Committee, on September 2019).

Informed Consent Statement: Written informed consent to use anonymized data of club members, who earlier consented to data collection by the club, was obtained from the club owner.

Data Availability Statement: The data analyzed during the study are available from the authors on reasonable request.

Conflicts of Interest: The authors declare no conflict of interest.

\section{References}

1. Reinders, I.; Visser, M.; Schaap, L. Body weight and body composition in old age and their relationship with frailty. Curr. Opin. Clin. Nutr. Metab. Care 2017, 20, 11-15. [CrossRef] [PubMed] 
2. Reinders, I.; Murphy, R.A.; Koster, A.; Brouwer, I.A.; Visser, M.; Garcia, M.E.; Launer, L.J.; Siggeirsdottir, K.; Eiriksdottir, G.; Jonsson, P.V.; et al. Muscle Quality and Muscle Fat Infiltration in Relation to Incident Mobility Disability and Gait Speed Decline: The Age, Gene/Environment Susceptibility-Reykjavik Study. J. Gerontol. A Biol. Sci. Med. Sci. 2015, 70, 1030-1036. [CrossRef] [PubMed]

3. Miljkovic, I.; Kuipers, A.L.; Cauley, J.A.; Prasad, T.; Lee, C.G.; Ensrud, K.E.; Cawthon, P.M.; Hoffman, A.R.; Dam, T.-T.; Gordon, C.L.; et al. Greater Skeletal Muscle Fat Infiltration Is Associated With Higher All-Cause and Cardiovascular Mortality in Older Men. J. Gerontol. A Biol. Sci. Med. Sci. 2015, 70, 1133-1140. [CrossRef] [PubMed]

4. García-Esquinas, E.; José García-García, F.; León-Muñoz, L.M.; Carnicero, J.A.; Guallar-Castillón, P.; Gonzalez-Colaço Harmand, M.; López-García, E.; Alonso-Bouzón, C.; Rodríguez-Mañas, L.; Rodríguez-Artalejo, F. Obesity, fat distribution, and risk of frailty in two population-based cohorts of older adults in Spain. Obesity 2015, 23, 847-855. [CrossRef] [PubMed]

5. Chung, J.-Y.; Kang, H.-T.; Lee, D.-C.; Lee, H.-R.; Lee, Y.-J. Body composition and its association with cardiometabolic risk factors in the elderly: A focus on sarcopenic obesity. Arch. Gerontol. Geriatr. 2013, 56, 270-278. [CrossRef]

6. Liberman, K.; Forti, L.N.; Beyer, I.; Bautmans, I. The effects of exercise on muscle strength, body composition, physical functioning and the inflammatory profile of older adults: A systematic review. Curr. Opin. Clin. Nutr. Metab. Care 2017, 20, 30-53. [CrossRef]

7. Menezes, A.R.; Lavie, C.J.; Milani, R.V.; Arena, R.A.; Church, T.S. Cardiac rehabilitation and exercise therapy in the elderly: Should we invest in the aged? J. Geriatr. Cardiol. 2012, 9, 68-75. [CrossRef]

8. Galloza, J.; Castillo, B.; Micheo, W. Benefits of Exercise in the Older Population. Phys. Med. Rehabil. Clin. N. Am. 2017, 28, 659-669. [CrossRef]

9. Fontana, L. Interventions to promote cardiometabolic health and slow cardiovascular ageing. Nat. Rev. Cardiol. 2018, 15, 566-577. [CrossRef]

10. Papa, E.V.; Dong, X.; Hassan, M. Resistance training for activity limitations in older adults with skeletal muscle function deficits: A systematic review. Clin. Interv. Aging 2017, 12, 955-961. [CrossRef]

11. Keogh, J.W.L.; O’Reilly, S.; O’Brien, E.; Morrison, S.; Kavanagh, J.J. Can Resistance Training Improve Upper Limb Postural Tremor, Force Steadiness and Dexterity in Older Adults? A Systematic Review. Sports Med. 2019, 49, 1199-1216. [CrossRef]

12. Stoever, K.; Heber, A.; Eichberg, S.; Brixius, K. Influences of Resistance Training on Physical Function in Older, Obese Men and Women With Sarcopenia. J. Geriatr. Phys. Ther. 2018, 41, 20-27. [CrossRef]

13. Paterson, D.H.; Warburton, D.E. Physical activity and functional limitations in older adults: A systematic review related to Canada's Physical Activity Guidelines. Int. J. Behav. Nutr. Phys. Act. 2010, 7, 38. [CrossRef]

14. Northey, J.M.; Cherbuin, N.; Pumpa, K.L.; Smee, D.J.; Rattray, B. Exercise interventions for cognitive function in adults older than 50: A systematic review with meta-analysis. Br. J. Sports Med. 2018, 52, 154-160. [CrossRef]

15. Peralta, M.; Martins, J.; Gómez Chávez, F.; Cortés Almanzar, P.; Marques, A. Self-rated wellbeing and physical activity associations in European older adults. Eur. J. Sport Sci. 2018, 18, 1038-1044. [CrossRef]

16. Westcott, W.L. Resistance training is medicine: Effects of strength training on health. Curr. Sports Med. Rep. 2012, 11, 209-216. [CrossRef]

17. Vaitkevicius, P.V.; Ebersold, C.; Shah, M.S.; Gill, N.S.; Katz, R.L.; Narrett, M.J.; Applebaum, G.E.; Parrish, S.M.; O'Connor, F.C.; Fleg, J.L. Effects of aerobic exercise training in community-based subjects aged 80 and older: A pilot study. J. Am. Geriatr. Soc. 2002, 50, 2009-2013. [CrossRef]

18. Sabbahi, A.; Arena, R.; Elokda, A.; Phillips, S.A. Exercise and Hypertension: Uncovering the Mechanisms of Vascular Control. Prog. Cardiovasc. Dis. 2016, 59, 226-234. [CrossRef]

19. Butcher, L.R.; Thomas, A.; Backx, K.; Roberts, A.; Webb, R.; Morris, K. Low-intensity exercise exerts beneficial effects on plasma lipids via PPARgamma. Med. Sci. Sports Exerc. 2008, 40, 1263-1270. [CrossRef]

20. Morat, T.; Krueger, J.; Gaedtke, A.; Preuss, M.; Latsch, J.; Predel, H.-G. Effects of 12 weeks of Nordic Walking and XCO Walking training on the endurance capacity of older adults. Eur. Rev. Aging Phys. Act. 2017, 14, 16. [CrossRef]

21. Cartee, G.D.; Hepple, R.T.; Bamman, M.M.; Zierath, J.R. Exercise Promotes Healthy Aging of Skeletal Muscle. Cell Metab. 2016, 23, 1034-1047. [CrossRef] [PubMed]

22. Park, W.; Jung, W.-S.; Hong, K.; Kim, Y.-Y.; Kim, S.-W.; Park, H.-Y. Effects of Moderate Combined Resistance- and Aerobic-Exercise for 12 Weeks on Body Composition, Cardiometabolic Risk Factors, Blood Pressure, Arterial Stiffness, and Physical Functions, among Obese Older Men: A Pilot Study. Int. J. Environ. Res. Public Health 2020, 17, 7233. [CrossRef] [PubMed]

23. Spence, A.L.; Carter, H.H.; Naylor, L.H.; Green, D.J. A prospective randomized longitudinal study involving 6 months of endurance or resistance exercise. Conduit artery adaptation in humans. J. Physiol. 2013, 591, 1265-1275. [CrossRef] [PubMed]

24. Takeshima, N.; Rogers, M.E.; Islam, M.M.; Yamauchi, T.; Watanabe, E.; Okada, A. Effect of concurrent aerobic and resistance circuit exercise training on fitness in older adults. Eur. J. Appl. Physiol. 2004, 93, 173-182. [CrossRef] [PubMed]

25. Adams, V.; Linke, A. Impact of exercise training on cardiovascular disease and risk. Biochim. Biophys. Acta Mol. Basis Dis. 2019, 1865, 728-734. [CrossRef] [PubMed]

26. Vega, R.B.; Konhilas, J.P.; Kelly, D.P.; Leinwand, L.A. Molecular Mechanisms Underlying Cardiac Adaptation to Exercise. Cell Metab. 2017, 25, 1012-1026. [CrossRef]

27. Che, L.; Li, D. The Effects of Exercise on Cardiovascular Biomarkers: New Insights, Recent Data, and Applications. Adv. Exp. Med. Biol. 2017, 999, 43-53. [CrossRef] 
28. Ferrucci, L.; Fabbri, E. Inflammageing: Chronic inflammation in ageing, cardiovascular disease, and frailty. Nat. Rev. Cardiol. 2018, 15, 505-522. [CrossRef]

29. Nystoriak, M.A.; Bhatnagar, A. Cardiovascular Effects and Benefits of Exercise. Front. Cardiovasc. Med. 2018, 5, 135. [CrossRef]

30. O'Donovan, G.; Hamer, M. The association between leisure-time physical activity and lung function in older adults: The English longitudinal study of ageing. Prev. Med. 2018, 106, 145-149. [CrossRef]

31. Hurst, C.; Weston, K.L.; McLaren, S.J.; Weston, M. The effects of same-session combined exercise training on cardiorespiratory and functional fitness in older adults: A systematic review and meta-analysis. Aging Clin. Exp. Res. 2019, 31, 1701-1717. [CrossRef]

32. WHO. Physical activity: Key facts. Available online: https://www.who.int/en/news-room/fact-sheets/detail/physical-activity (accessed on 12 May 2020).

33. Rodríguez-Gómez, I.; Mañas, A.; Losa-Reyna, J.; Alegre, L.M.; Rodríguez-Mañas, L.; García-García, F.J.; Ara, I. Relationship between Physical Performance and Frailty Syndrome in Older Adults: The Mediating Role of Physical Activity, Sedentary Time and Body Composition. Int. J. Environ. Res. Public Health 2020, 18, 203. [CrossRef]

34. Edwards, S. High performance training and racing. In Heart Rate Monit Book; Feet Fleet Press: Sacramento, CA, USA, 1993; Volume 349, pp. 113-123.

35. Krzymińska-Siemaszko, R.; Fryzowicz, A.; Czepulis, N.; Kaluźniak-Szymanowska, A.; Dworak, L.B.; Wieczorowska-Tobis, K. The impact of the age range of young healthy reference population on the cut-off points for low muscle mass necessary for the diagnosis of sarcopenia. Eur. Rev. Med. Pharmacol. Sci. 2019, 23, 4321-4332. [CrossRef]

36. Krzymińska-Siemaszko, R.; Czepulis, N.; Lewandowicz, M.; Zasadzka, E.; Suwalska, A.; Witowski, J.; Wieczorowska-Tobis, K. The Effect of a 12-Week Omega-3 Supplementation on Body Composition, Muscle Strength and Physical Performance in Elderly Individuals with Decreased Muscle Mass. Int. J. Environ. Res. Public Health 2015, 12, 10558-10574. [CrossRef]

37. Marini, E.; Campa, F.; Buffa, R.; Stagi, S.; Matias, C.N.; Toselli, S.; Sardinha, L.B.; Silva, A.M. Phase angle and bioelectrical impedance vector analysis in the evaluation of body composition in athletes. Clin. Nutr. 2020, 39, 447-454. [CrossRef]

38. Wannamethee, S.G.; Atkins, J.L. Muscle loss and obesity: The health implications of sarcopenia and sarcopenic obesity. Proc. Nutr. Soc. 2015, 74, 405-412. [CrossRef]

39. Batsis, J.A.; Villareal, D.T. Sarcopenic obesity in older adults: Aetiology, epidemiology and treatment strategies. Nat. Rev. Endocrinol. 2018, 14, 513-537. [CrossRef]

40. Timmons, J.F.; Minnock, D.; Hone, M.; Cogan, K.E.; Murphy, J.C.; Egan, B. Comparison of time-matched aerobic, resistance, or concurrent exercise training in older adults. Scand. J. Med. Sci. Sports 2018, 28, 2272-2283. [CrossRef]

41. Lima, L.G.; Bonardi, J.T.; Campos, G.O.; Bertani, R.F.; Scher, L.M.; Moriguti, J.C.; Ferriolli, E.; Lima, N.K. Combined aerobic and resistance training: Are there additional benefits for older hypertensive adults? Clinics 2017, 72, 363-369. [CrossRef]

42. Schroeder, E.C.; Franke, W.D.; Sharp, R.L.; Lee, D.-C. Comparative effectiveness of aerobic, resistance, and combined training on cardiovascular disease risk factors: A randomized controlled trial. PLoS ONE 2019, 14, e0210292. [CrossRef]

43. Dos Santos, L.; RIBEIRO, A.S.; NUNES, J.P.; Tomeleri, C.M.; Nabuco, H.C.G.; NASCIMENTO, M.A.; Sugihara Junior, P.; Fernandes, R.R.; Campa, F.; Toselli, S.; et al. Effects of Pyramid Resistance-Training System with Different Repetition Zones on Cardiovascular Risk Factors in Older Women: A Randomized Controlled Trial. Int. J. Environ. Res. Public Health 2020, 17, 6115. [CrossRef]

44. Fisher, G.; McCarthy, J.P.; Zuckerman, P.A.; Bryan, D.R.; Bickel, C.S.; Hunter, G.R. Frequency of combined resistance and aerobic training in older women. J. Strength Cond. Res. 2013, 27, 1868-1876. [CrossRef]

45. Nascimento, M.A.D.; Gerage, A.M.; Silva, D.R.P.D.; Ribeiro, A.S.; Machado, D.G.D.S.; Pina, F.L.C.; Tomeleri, C.M.; Venturini, D.; Barbosa, D.S.; Mayhew, J.L.; et al. Effect of resistance training with different frequencies and subsequent detraining on muscle mass and appendicular lean soft tissue, IGF-1, and testosterone in older women. Eur. J. Sport Sci. 2019, 19, 199-207. [CrossRef]

46. Murlasits, Z.; Reed, J.; Wells, K. Effect of resistance training frequency on physiological adaptations in older adults. J. Exerc. Sci. Fit. 2012, 10, 28-32. [CrossRef]

47. Pina, F.L.C.; NUNES, J.P.; NASCIMENTO, M.A.; RIBEIRO, A.S.; Mayhew, J.L.; CYRINO, E.S. Similar Effects of 24 Weeks of Resistance Training Performed with Different Frequencies on Muscle Strength, Muscle Mass, and Muscle Quality in Older Women. Int. J. Exerc. Sci. 2019, 12, 623-635. [PubMed]

48. Ihalainen, J.K.; Inglis, A.; Mäkinen, T.; Newton, R.U.; Kainulainen, H.; Kyröläinen, H.; Walker, S. Strength Training Improves Metabolic Health Markers in Older Individual Regardless of Training Frequency. Front. Physiol. 2019, 10, 32. [CrossRef] [PubMed]

49. Turpela, M.; Häkkinen, K.; Haff, G.G.; Walker, S. Effects of different strength training frequencies on maximum strength, body composition and functional capacity in healthy older individuals. Exp. Gerontol. 2017, 98, 13-21. [CrossRef] [PubMed]

50. Toselli, S.; Badicu, G.; Bragonzoni, L.; Spiga, F.; Mazzuca, P.; Campa, F. Comparison of the Effect of Different Resistance Training Frequencies on Phase Angle and Handgrip Strength in Obese Women: A Randomized Controlled Trial. Int. J. Environ. Res. Public Health 2020, 17, 1163. [CrossRef] [PubMed]

51. Huang, G.; Wang, R.; Chen, P.; Huang, S.C.; Donnelly, J.E.; Mehlferber, J.P. Dose-response relationship of cardiorespiratory fitness adaptation to controlled endurance training in sedentary older adults. Eur. J. Prev. Cardiol. 2016, 23, 518-529. [CrossRef]

52. van Roie, E.; Bautmans, I.; Coudyzer, W.; Boen, F.; Delecluse, C. Low- and High-Resistance Exercise: Long-Term Adherence and Motivation among Older Adults. Gerontology 2015, 61, 551-560. [CrossRef]

53. Fisher, J.P.; Steele, J.; Gentil, P.; Giessing, J.; Westcott, W.L. A minimal dose approach to resistance training for the older adult; the prophylactic for aging. Exp. Gerontol. 2017, 99, 80-86. [CrossRef] 
54. Miller, K.J.; Mesagno, C.; McLaren, S.; Grace, F.; Yates, M.; Gomez, R. Exercise, Mood, Self-Efficacy, and Social Support as Predictors of Depressive Symptoms in Older Adults: Direct and Interaction Effects. Front. Psychol. 2019, 10. [CrossRef]

55. de Oliveira, L.d.S.S.C.B.; Souza, E.C.; Rodrigues, R.A.S.; Fett, C.A.; Piva, A.B. The effects of physical activity on anxiety, depression, and quality of life in elderly people living in the community. Trends Psychiatry Psychother. 2019, 41, 36-42. [CrossRef]

56. Yasunaga, A.; Shibata, A.; Ishii, K.; Koohsari, M.J.; Oka, K. Cross-sectional associations of sedentary behaviour and physical activity on depression in Japanese older adults: An isotemporal substitution approach. BMJ Open 2018, 8, e022282. [CrossRef]

57. Kekäläinen, T.; Kokko, K.; Sipilä, S.; Walker, S. Effects of a 9-month resistance training intervention on quality of life, sense of coherence, and depressive symptoms in older adults: Randomized controlled trial. Qual. Life Res. 2018, 27, 455-465. [CrossRef]

58. Campa, F.; Silva, A.M.; Matias, C.N.; Monteiro, C.P.; Paoli, A.; NUNES, J.P.; Talluri, J.; Lukaski, H.; Toselli, S. Body Water Content and Morphological Characteristics Modify Bioimpedance Vector Patterns in Volleyball, Soccer, and Rugby Players. Int. J. Environ. Res. Public Health 2020, 17, 6604. [CrossRef] 